Check for updates

Montreal, Canada

Cite this as: BMJ 2020;371:m4182 http://dx.doi.org/10.1136/bmj.m4182 Published: 29 October 2020

\section{Covid-19: Mexico acknowledges 50000 more deaths than official figures show}

\author{
Owen Dyer
}

Mexico has lost 50 ooo more people to covid-19 than the 88924 counted in official figures, the director of the National Centre for Preventive Programs and Disease Control, Ruy López Ridaura, told a press conference this week, relating the conclusion of a health ministry study into excess deaths.

Behind him, a graph that plotted all-cause mortality in 2020 against the 2015-18 average showed a huge spike beginning in April. Weekly deaths reached double the expected level in mid-July, then fell again, to hover at about $30 \%$ above expected deaths on 26 September, the end of the studied period. ${ }^{1}$

The number of deaths seen in these first 39 weeks of 2020 was 193170 higher than the expected 524920 . The ministry reviewed death certificates, counting as covid-19 all cases of atypical pneumonia and respiratory distress syndrome, plus certificates containing various keywords associated with the coronavirus. Those who had tested negative while ill were not counted.

This led to a preliminary estimate, said Ridaura, of 139153 covid-19 deaths in Mexico up to 26 September, meaning that $72 \%$ of the excess mortality could be attributed directly to covid-19.

Such a figure would increase Mexico's toll by $64 \%$ and make it third in the world for covid-19 deaths, leapfrogging India-although India might also detect higher mortality if it performed a similar analysis.

It would mean that Mexico has lost more than 1 in 1000 citizens to the virus, a milestone so far officially passed only by Peru and San Marino.

Men have accounted for $66 \%$ of excess deaths in Mexico this year. While the over 65 age group had the highest absolute number of excess deaths, the probability of dying increased most sharply in those aged 45-64. This group's overall mortality was up $63 \%$ from an average year, compared with $33 \%$ in the over 65 s and $18 \%$ in those aged 20-44. The under-2os had lower than usual mortality this year.

In recent weeks, as the virus has ebbed since its July peak, the number of excess deaths is barely higher than the number of registered covid-19 deaths, Ridaura noted. But new cases have begun ticking up again in the past few days.

Mexico's hospitals have struggled with absenteeism and health worker infections. The country's president, Andrés Manuel López Obrador, widely known as AMLO, has been compared to a left wing Bolsonaro or Trump for his dismissive attitude to the virus. He is often seen unmasked, hugging supporters. But he has left government scientists largely unmolested in their work.

Mexico has an extremely low testing rate, just 18124 tests per million population to date, and the government has acknowledged for months that its official figures are undercounts. The new mortality figures have yet to enter Mexico's official tally and be reflected in global figures. They would raise the current worldwide death toll of covid-19 by $4.25 \%$, to 1228764 .

1 Ridaura RL. Presentation on the estimation of excess mortality. October 2020. www.youtube.com/watch?V=VqYIV9-CK9E. 